\title{
Effects of the hybrid composition of commercial lithium-ion capacitors on their floating aging
}

\author{
Nagham El Ghossein*, Ali Sari, Pascal Venet \\ Univ Lyon, Université Lyon 1, \\ AMPERE, UMR CNRS 5005, \\ 69100 Villeurbanne, France
}

* Laboratoire Ampère, Université Lyon 1, 69100 Villeurbanne, nagham.el-ghossein@univ-lyon1.fr.

Abstract - Lifetime of Energy Storage Systems (ESSs) is a key factor that is extremely influenced by the operating conditions. For this reason, Lithium-ion Batteries (LiBs) and Supercapacitors (SCs) were subjected to accelerated aging tests in several previous research in order analyze their lifespan. Lithium-ion Capacitors (LiCs), which fall in between LiBs and SCs, are still considered as a novel technology. Their behavior during accelerated aging tests is not yet well studied in the literature. This paper focuses on studying the degradation of their properties during floating aging. Eighteen samples were tested under three different voltage values and two different temperatures over twenty months. Cells that were discharged to the minimum voltage showed a severe capacitance decrease that was much higher than the one of fully charged cells. The best storage voltage of LiCs was found to be $3 \mathrm{~V}$, which is equivalent to a half charging state. The hybrid structure of LiCs was found to be the major cause of this change in behavior during aging at different voltages. Mechanisms that affect the electrodes and the internal composition of the cells in the diverse conditions were analyzed and predicted.

Index Terms—Lithium-ion capacitor, floating aging, aging mechanisms, performance degradation, lifetime analysis.

\section{INTRODUCTION}

Energy Storage Systems (ESSs) are increasingly gaining attention in a world threatened by global warming. Renewable energy sources, which aim to replace conventional electricity generation techniques, profit from these devices that can store the generated energy and enhance power quality [1-3]. Moreover, transportation facilities, which extremely contribute in the rise of pollution, have been lately employing ESSs in order to limit their harmful emissions [4, 5]. Different types of ESSs were used for these purposes such as batteries, supercapacitors and hybrid systems combining both of them [6-8].

Among all categories of batteries, Lithium-ion Batteries (LiBs) have proven promising characteristics. Their storage of energy that is based on electrochemical reactions between two electrodes separated by an electrolyte make them high energy sources [9]. In addition, Supercapacitors (SCs) are known for their power density and lifetime higher than that of LiBs since the storage of energy in these devices is based on fast electrostatic mechanisms [10]. A new hybrid supercapacitor combining the 
electrochemical characteristics of the former ESSs was developed in order to relatively ensure both high power and energy densities $[11,12]$. The new hybrid device is known by the Lithium-ion Capacitor ( $\mathrm{LiC})$ that has a negative electrode similar to the negative electrode of LiBs and a positive electrode similar to the positive electrode of SCs.

Since ESSs are electrochemical devices, their behavior and their lifespan depend on their working conditions such as temperature, voltage and current [13]. Therefore, prior to their integration in any application, evaluating their lifetime in the corresponding conditions seems particularly beneficial [14-16]. This can avoid future failure and reduce the cost of the overall system $[17,18]$. In order to assess this criterion, accelerated aging tests are applied to ESSs by using stresses that induce their degradation. Two types of tests are usually performed: calendar aging and cycle aging $[10,15,19,20]$. Calendar aging aims to study the effects of constant temperature and voltage on the performance of the ESS. Thus, the behavior of the ESS at rest, which could be during its storage, is revealed. When the cells are maintained on a float charge mode during aging, this type of process can be referred to as floating aging [10]. On the other hand, cycle aging provides information on the deterioration of the ESS on duty. Specific current profiles are applied to the system so the resulting loss of performance could be analyzed [21-23]. Several previous research had studied the effects of both aging tests on LiBs and SCs $[13,14,20,24]$. Based on the deterioration of the electrical characteristics throughout the process, the aging mechanisms were predicted and analyzed [10, 15]. However, lifetime of LiCs is not yet well studied in the literature. Only one research paper had assessed the aging of LiCs in spacecraft applications [25]. Calendar aging tests were done at high and low temperatures while charging the cells to high voltage values. An aging model was then established based on their capacitance degradation. Nevertheless, a physicochemical analysis that describes the causes of the capacitance decrease and the resistance increase was missing.

This paper focuses on the floating aging of LiCs at high temperatures and different voltage values. Since LiCs are hybrid components, the electrochemical processes that engender the storage of energy differ from one state of charge to another. Therefore, the novelty of this study concerns the use of three states of charge that are electrochemically meaningful to accelerate the aging of LiCs and the establishment of a physicochemical analysis afterwards. The best storage condition that ensures the minimum loss of performance of LiCs during storage will be introduced for the first time in this paper.

As for the organization of the paper, section II will present the operating principle of LiCs that explains the choice of the voltage values during aging. Different conditions of the accelerated tests will be introduced as well. Throughout the aging process, the properties of the tested cells were followed using impedance measurements. Therefore, section III will be dedicated to the presentation of this measurement technique. The results of the aging process and the analysis of the possible aging mechanisms responsible for the performance degradation will also be developed in this section. 


\section{Operating PRINCIPE}

In order to assure high energy and power densities, the negative electrode of a LiB was combined with the positive electrode of a SC to form the LiC. Commercial cells are made of a negative electrode of carbon pre-doped with lithium and a positive electrode of activated carbon [11]. Electrodes are separated by an electrolyte that is usually used in LiBs. It is made of the lithium salt $\mathrm{LiPF}_{6}$ in an organic solvent like the ethylene carbonate and dimethyl carbonate (EC/DMC). Such devices operate over a voltage window ranging from 2.2 to $3.8 \mathrm{~V}[26]$.

At the negative electrode, redox reactions similar to the ones in a LiB happen. Small particle size of the electrode should be assured in order to ensure fast redox reactions that increase the power density of the device [27]. At the positive electrode, the double layer formed by the ions near the charged activated carbon electrode take place similarly to SCs. This electrode should have an improved specific area in order to balance the high capacitance of the negative electrode [27]. Due to the hybrid structure of a LiC, the operating voltage window could be divided into 2 parts [28]. In fact, the open circuit voltage of the LiC is around $3 \mathrm{~V}$ [29]. Discharging the cell from 3 to $2.2 \mathrm{~V}$ induces the deintercalation of the lithium ions $\mathrm{Li}^{+}$from the pre-doped carbon negative electrode and their movement towards the surface of the positive electrode [30]. On the other hand, charging the cell from 3 to $3.8 \mathrm{~V}$ causes the dissociation of the salt $L i P F_{6}$ into cations $L i^{+}$and anions $P F_{6}^{-}$. This initiates the movement of the anions towards the surface of the activated carbon and the intercalation of the cations into carbon layers of the negative electrode $[28,31]$.

Therefore, at 2.2, 3 and 3.8 V, the positive electrode of a LiC possesses different states. In order to analyze the effects of each state on the aging of the $\mathrm{LiC}$, these values were chosen to be the tested voltages during floating aging. Based on previous research on the electrochemical phenomena in a LiC cell [28-31], Fig. 1 was plotted in order to summarize the chemical behavior of the LiC at the spotted voltages.

LiCs (Ultimo Prismatic Cells) developed by JM Energy and JSR Micro were chosen to be tested. Table 1 recapitulates their main properties. As the maximum temperature that could be supported by these cells is equal to $70^{\circ} \mathrm{C}$, it was chosen to accelerate their aging. An additional temperature of $60^{\circ} \mathrm{C}$ was also used for further comparison.

\section{FloAting AgING}

Each aging condition was applied on three samples so reproducible and accurate results are guaranteed. Table II shows the distribution of the samples on different aging conditions taking into account temperature and voltage.

Float Charge (FC) of the cells is used during the whole aging process in order to maintain the voltage of the cells constant. The impedance of the cells was regularly measured so its evolution could be spotted at several aging stages. 


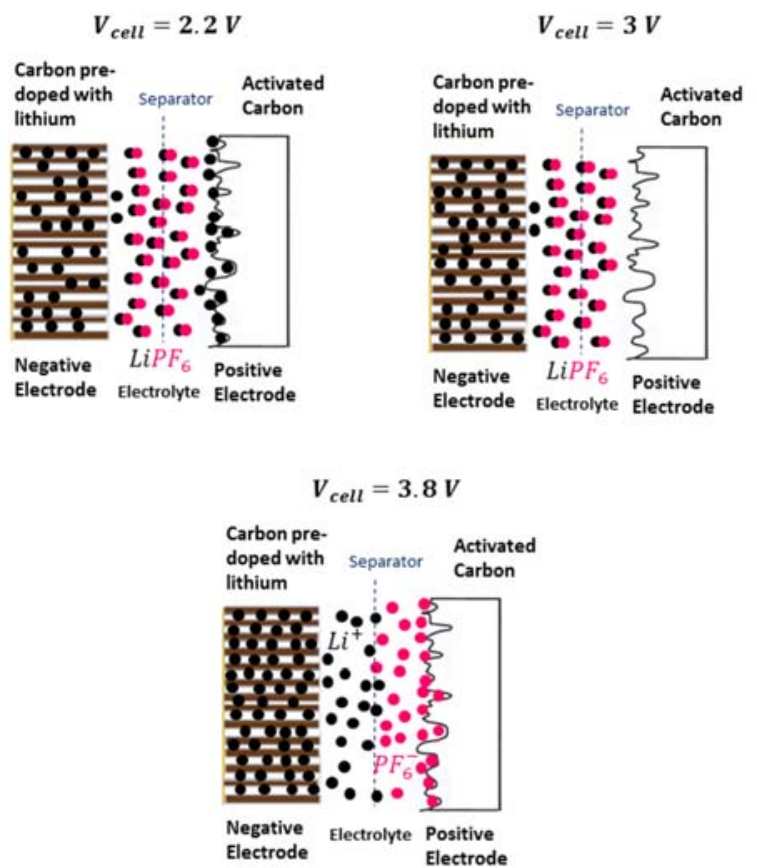

Fig. 1. The chemical composition of a $\mathrm{LiC}$ at $2.2,3$ and $3.8 \mathrm{~V}$.

TABLE I

CHARACTERISTICS OF LIC CELLS.

\begin{tabular}{|l|c|}
\hline Voltage range (V) & $2.2-3.8$ \\
\hline Capacitance (F) & 3300 \\
\hline Energy density (Wh/kg) & 13 \\
\hline $\begin{array}{l}\text { Equivalent series resistance at } \mathbf{1} \\
\mathbf{k H z}(\mathbf{m} \Omega)\end{array}$ & 0.7 \\
\hline Power density (kW/kg) & 10 \\
\hline Temperature range $\left.{ }^{\circ} \mathbf{C}\right)$ & $-30-70$ \\
\hline
\end{tabular}

TABLE II

DISTRIBUTION OF LIC CELLS ON DIFFERENT TEMPERATURE AND VOLTAGE CONDITIONS.

\begin{tabular}{|c|c|c|}
\cline { 2 - 3 } \multicolumn{1}{c|}{} & \multicolumn{2}{c|}{ Float Charge (FC) } \\
\hline Temperature $\left({ }^{\circ} \mathrm{C}\right)$ & Voltage $(\mathrm{V})$ & Number of cells \\
\hline \multirow{3}{*}{60} & 2.2 & 3 \\
\cline { 2 - 3 } & 3 & 3 \\
\cline { 2 - 3 } & 3.8 & 3 \\
\hline \multirow{3}{*}{70} & 2.2 & 3 \\
\cline { 2 - 3 } & 3 & 3 \\
\cline { 2 - 3 } & 3.8 & 3 \\
\hline
\end{tabular}

\section{A. Periodic Impedance Measurements}

Electrochemical Impedance Spectroscopy (EIS) was the tool for finding the impedance of the cells. This measurement technique is frequently used for the characterization of ESSs [12, 32-36]. The impedance was measured at different aging times and the normalized capacitance and resistance were calculated accordingly. These two properties measured at $100 \mathrm{mHz}$ and at the aging voltage were used to follow the aging of the LiC cells. 


\section{B. Experimental Test Bench}

The eighteen samples were installed in two separate climatic chambers at $60^{\circ} \mathrm{C}$ and $70^{\circ} \mathrm{C}$. Fig. 2 shows one of these chambers in which LiCs are mounted and connected to external terminals that facilitate the measurements done at the tests temperatures. During the aging process, cells were connected to power supplies in order to ensure the continuous float charge. LiCs aging at the same voltage value were connected in parallel.

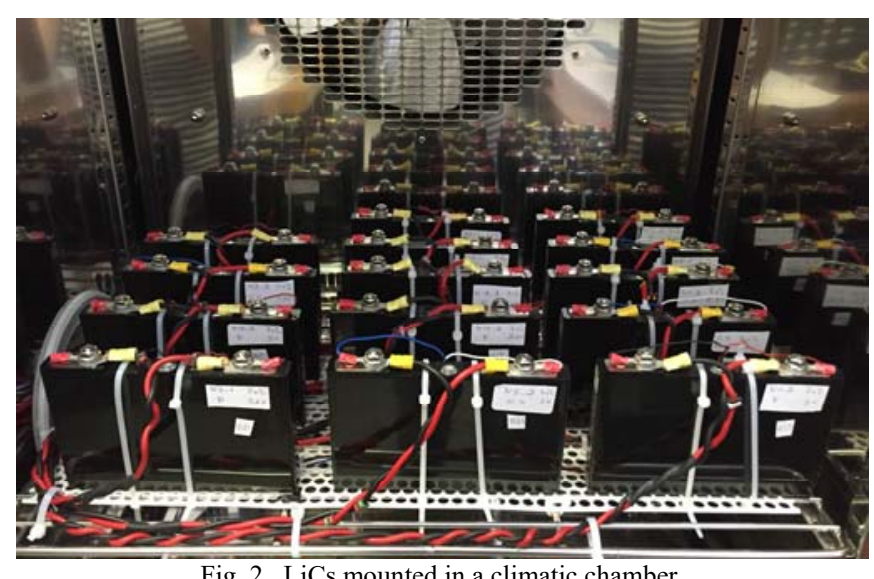

Fig. 2. LiCs mounted in a climatic chamber.

\section{Aging Results}

After 20 months of floating aging, the rate of degradation varied extensively from one condition to another. Some of the cells aging at $3.8 \mathrm{~V}$ encountered swelling issues. Therefore, their corresponding accelerated aging tests were stopped after 17 months. Fig. 3 and 4 show the evolution of the normalized capacitance and resistance with respect to the aging time at the two tested temperatures. Each curve represents one sample.

Comparing Fig. 3 and 4, one can conclude that the highest the temperature is, the highest the rate of degradation becomes. This was also commonly found in research studying the aging of LiBs $[15,16,20,21,23,37,38]$ and SCs $[10,13,19]$. In fact, for $\mathrm{LiC}$ cells aging at $2.2 \mathrm{~V}$, the capacitance decrease reaches around $51 \%$ at $60^{\circ} \mathrm{C}$ and $55 \%$ at $70^{\circ} \mathrm{C}$ respectively. As for the resistance, $12 \%$ was added to its value at $60^{\circ} \mathrm{C}$ and $14 \%$ at $70^{\circ} \mathrm{C}$. Cells aging at $3.8 \mathrm{~V}$ have less capacitance decrease. When the values of the corresponding cells are averaged, the decrease is equal to $18 \%$ at $60^{\circ} \mathrm{C}$ and $40 \%$ at $70^{\circ} \mathrm{C}$. On the other hand, an important difference in the increase of the resistance is noticed. Two cells that belong to a specific production batch have around $74 \%$ and $95 \%$ of increase in the resistance at $60^{\circ} \mathrm{C}$ and $70^{\circ} \mathrm{C}$ respectively after 17 months of aging. As for the other cells that come from another production batch, the resistance increase is around $26 \%$ after 20 months at $60^{\circ} \mathrm{C}$ and $60 \%$ after 17 months at $70^{\circ} \mathrm{C}$. These differences between curves aging in the same conditions might be related to small differences in the internal constitution of the cells between one production batch and another. The rest of LiCs that were aging at $3 \mathrm{~V}$, have a small capacitance decrease. They lost around $2.5 \%$ at $60^{\circ} \mathrm{C}$ and $7 \%$ at $70^{\circ} \mathrm{C}$. The resistance increase is also insignificant; $4 \%$ at $60^{\circ} \mathrm{C}$ 
and $6 \%$ at $70^{\circ} \mathrm{C}$. Impedance measurements at $25^{\circ} \mathrm{C}$ were also applied to the cells before and after aging in order to validate the aging results. Fig. 5 compares the capacitance decrease and the resistance increase, measured at $25^{\circ} \mathrm{C}$, of 6 cells that aged at different temperatures and different voltage values. Higher temperature clearly induces higher deterioration of the cells.

These results show that leaving LiCs at a low state of charge induces their deterioration, while fully charging them also harms their performance but less than fully discharging them to the minimum voltage of $2.2 \mathrm{~V}$. The best way to extend their lifetime is to half charge them. This behavior of LiCs is particular. In fact, according to $[13,19]$, the capacitance of SCs during calendar aging decreases with the test voltage increase. A high state of charge induces a high drop of the capacitance after several months of accelerated aging. This applies to the majority of the LiBs too. In fact, since many chemistries belong to the LiB type, the effects of temperature and voltage differ from one chemistry to another. However, for most of them, a low state of charge provokes less capacity decrease than a high state of charge [16, 39-42].

In order to explain this specific aging behavior of LiCs, the aging mechanisms generated by their hybrid composition were analyzed at each voltage value.

\section{Aging Mechanisms}

Since the negative electrode of a $\mathrm{LiC}$ is made of carbon similarly to LiBs, it is worthwhile to recall the main aging mechanisms of this type of electrodes. According to the literature, it has the major effect on the aging of LiBs because at its interface with the electrolyte, the organic electrolyte is highly reactive with the components of the electrode [43]. In fact, at the negative side of the cell, the operation of the electrode is over a voltage window that does not cover the electrochemical stability range of the electrolyte. Therefore, its components are reduced at the surface of the electrode forming a protective layer called the Solid Electrolyte Interface (SEI). This often happens when the electrode is fully charged, which is equivalent to a total intercalation of lithium ions into carbon layers $[44,45]$. During the lifetime of the battery, this SEI might grow and enter into

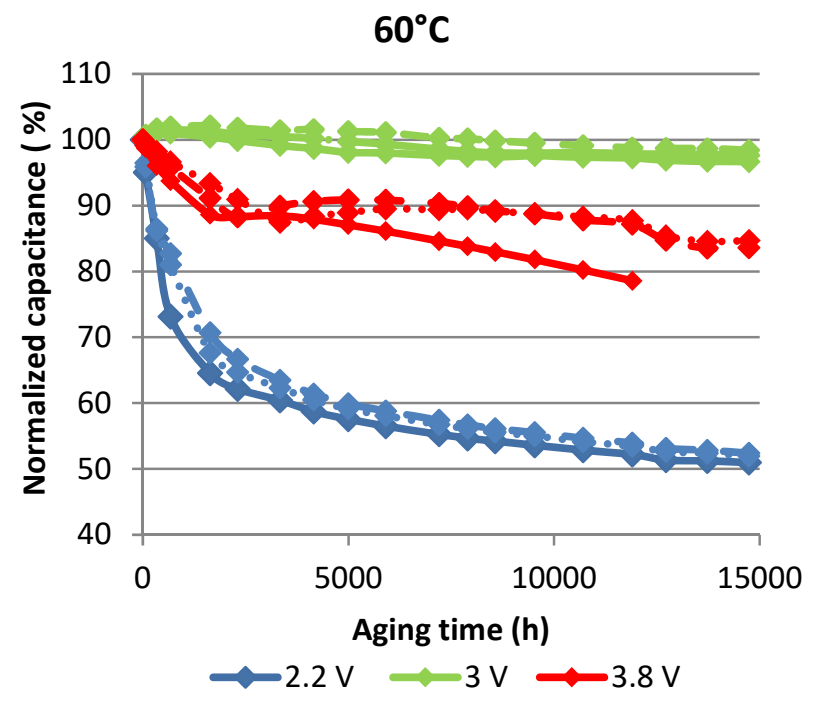




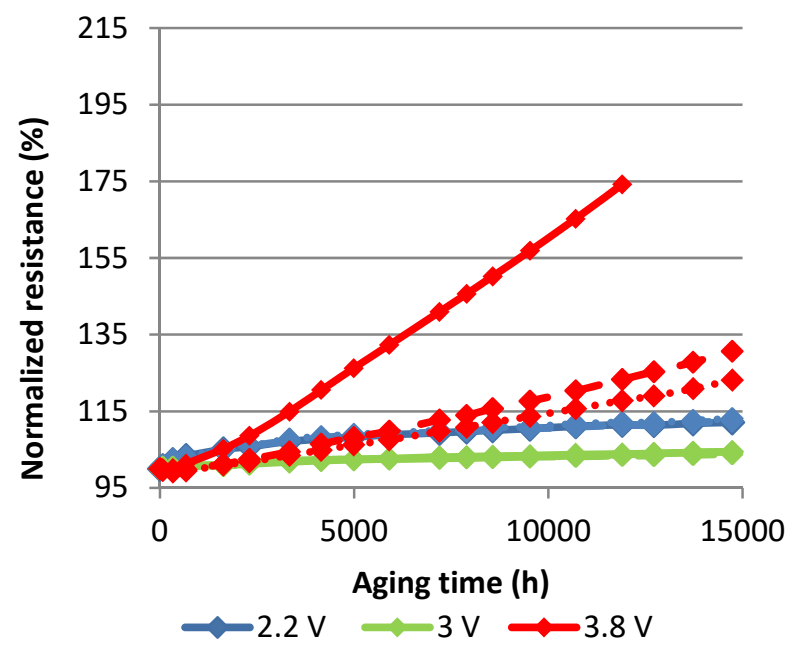

Fig. 3. Capacitance and resistance evolution after 20 months of aging at $60^{\circ} \mathrm{C}$. Each curve belongs to one tested $\mathrm{LiC}$.
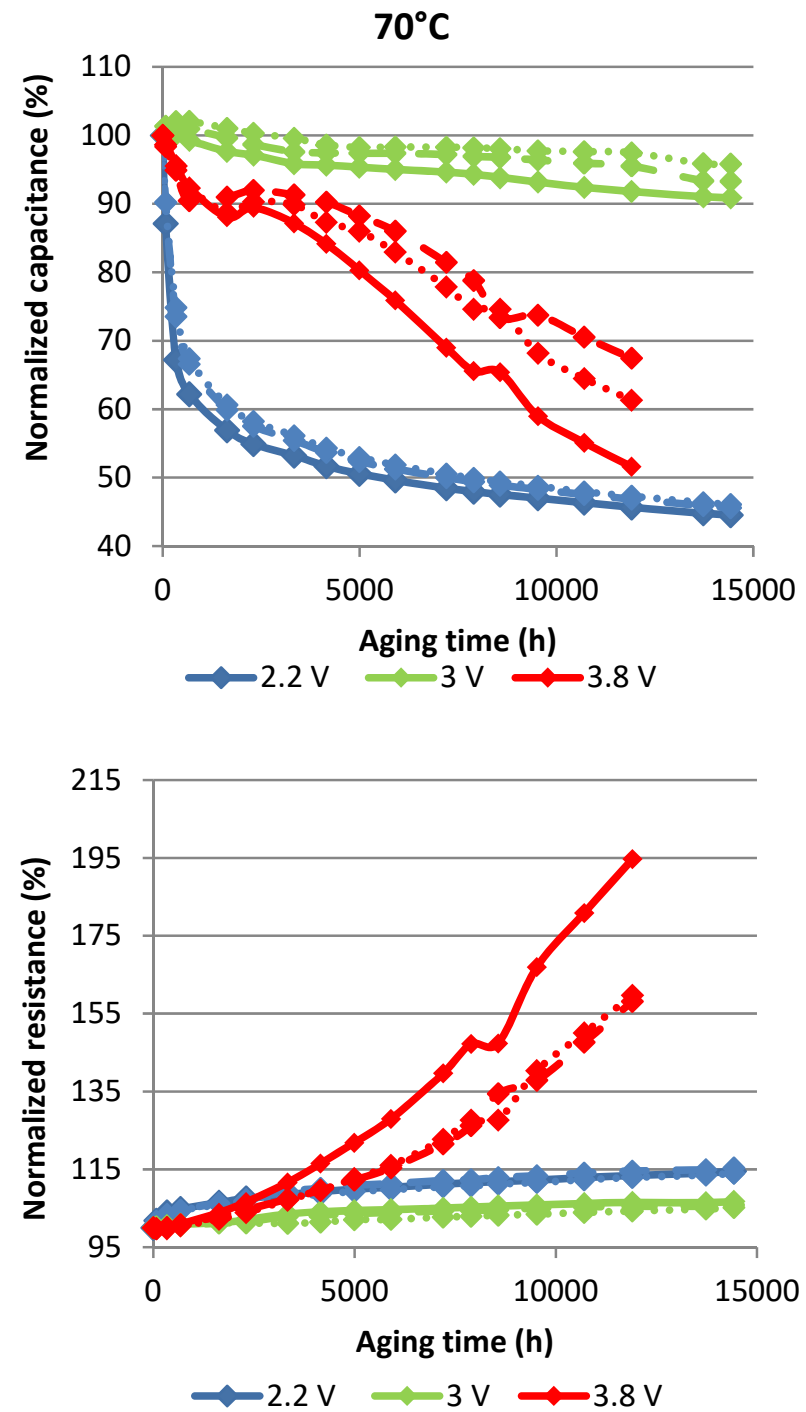

Fig. 4. Capacitance and resistance evolution after one 20 months of aging at $70^{\circ} \mathrm{C}$. Each curve belongs to one tested LiC. 


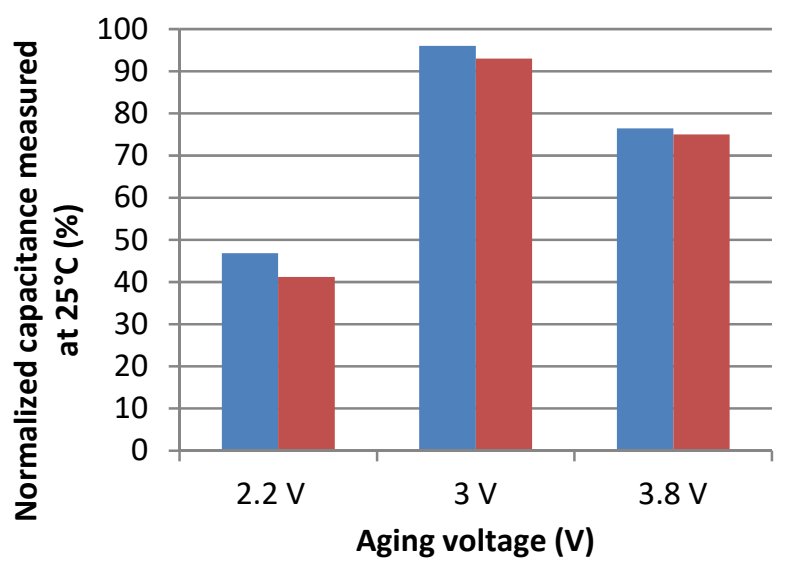

Aging temperature: $60^{\circ} \mathrm{C}$

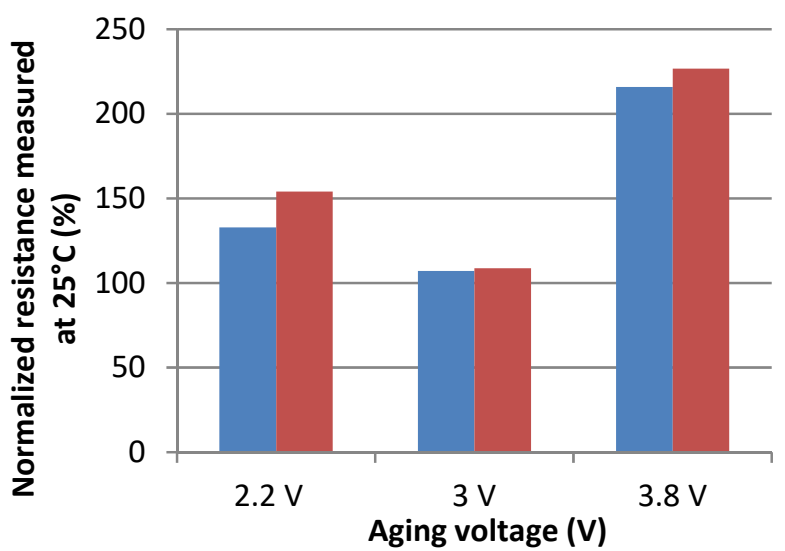

Aging temperature: $60^{\circ} \mathrm{C}$ Aging temperature: $70^{\circ} \mathrm{C}$

Fig. 5. Comparison between the normalized capacitance and resistance measured at $25^{\circ} \mathrm{C}$ of cells aged at different conditions. into the pores of the electrode and even in those of the separator. As a consequence, the surface area that can be reached by the ions diminishes. Therefore, the growth of this layer induces the increase of the impedance of the cell during aging [46]. Moreover, reactions contributing to the formation of this layer may generate gases that cause the deterioration of the electrode [47]. Lithium plating might also occur at the negative electrode especially when its potential is very low [48].

The positive electrode of a $\mathrm{LiC}$ is similar to the one of a SC. However, aging mechanisms could not be considered completely the same because the electrolyte solution used in LiCs differs from the electrolyte employed in conventional SCs. Activated carbon electrodes of a SC are treated chemically and thermally in order to produce nanopores that enhance the capacity of storage [49]. Some surface groups, known as parasitic groups, reside after the process. They are oxygenated phenol, carboxyl, and carbonyl groups $[10,50]$. At high temperatures and voltages, redox reactions may occur between them and the components of the electrolyte. This may lead to gas generation that increases the pressure in the cell. Electrode cracks may result afterwards. Solid products of these reactions may also be deposited on the surface of the activated carbon causing the blocking of pores [10, 51]. The surface of the electrode is modified because of the precipitated insulating products. With increasing aging, the portion 
of surface covered with these elements increases. As a result, the ability of the device to store energy decreases. These mechanisms initiate the decrease of the overall capacitance and the increase of the resistance. The microstructure of the activated carbon electrodes are also affected due to the consequent change of the size of pores [52].

Using this background information on the aging of both electrodes, the causes of LiCs degradation during floating aging were analyzed. In fact, observing the compositions of the cell in Fig. 1 at $2.2 \mathrm{~V}$ and $3.8 \mathrm{~V}$, the main differences were spotted:

- The negative electrode at $2.2 \mathrm{~V}$ is less lithiated than the negative electrode at $3.8 \mathrm{~V}$.

- The positive electrode at $2.2 \mathrm{~V}$ has the cations $\mathrm{Li}^{+}$accumulated at its surface while the positive electrode at $3.8 \mathrm{~V}$ has the anions $\mathrm{PF}_{6}^{-}$accumulated.

Regarding the first point, in [53] it was proven that, during calendar aging, the lower the potential of the negative electrode is, the higher the capacitance fade becomes. Knowing that lithiation decreases the potential of the electrode leads to deducing that the negative electrode of a $\mathrm{LiC}$ at $2.2 \mathrm{~V}$ is less aged than the one at $3.8 \mathrm{~V}$ because it is less lithiated. However, according to Fig. 3 and Fig. 4, cells aging at $2.2 \mathrm{~V}$ have higher capacitance decrease than cells aging at $3.8 \mathrm{~V}$. Therefore, one can conclude that the main contribution on the capacitance decrease of cells aging at $2.2 \mathrm{~V}$ comes from the positive electrode having the cations $L i^{+}$on its surface. Since the accumulation of $\mathrm{Li}^{+}$on the surface of the activated carbon is a phenomenon specific to LiCs, little research had investigated its effects. In [54], a SC composed of two activated carbon electrodes and an electrolyte similar to the one used in LiCs was studied. A potential drift of the activated carbon electrodes was noticed after several cycles. One possible reason behind this loss of performance was suggested to be the irreversible adsorption of the cations $\mathrm{Li}^{+}$by the parasitic groups present on the surface of the activated carbon. However, this is still unclearly explained in the literature [55, 56]. The huge decrease of the capacitance of the cells aging at $2.2 \mathrm{~V}$ could be then related to the interactions between the cations $\mathrm{Li}^{+}$that are already accumulated on the surface of the activated carbon and the functional groups present there. Products of these reactions would have blocked the pores of the activated carbon at the positive side and decreased the active surface. This storage condition should be avoided; LiCs should not be discharged to the minimum voltage when stored. It is recommended to maintain their voltage at $3 \mathrm{~V}$.

The mechanisms behind the loss of performance of cells aging at $3.8 \mathrm{~V}$ are different. In fact, swelling of these LiCs was noticed after several months of aging. This is a typical aging effect in LiBs and SCs as well. The negative electrode fully lithiated in LiCs at 3.8 V would suffer from the growth of the SEI $[44,45]$. As mentioned previously, this layer would decrease the active surface that can be attained by the ions and increase the overall impedance of the cells. This would explain the huge increase of their resistance in Fig. 3 and Fig. 4. Moreover, gases generated during the reactions forming this layer would contribute in the swelling of the cells. In addition, the potential of the aged negative electrode would increase due to the loss of lithium-ions. Therefore, in order to maintain a total voltage of $3.8 \mathrm{~V}$, due to the continuous float charge, the potential of the positive electrode 
would drift to more positive values. This induces the decomposition of electrolyte molecules at the positive side of the cells [57]. As a result, they may react with the parasitic groups present on the surface of the positive electrode made of activated carbon and generate more gases causing the swelling of the LiCs. For example, in [58], it was suggested that the high polarization of the positive electrode, (above $4 \mathrm{VVS} \mathrm{Li/Li+}$ ), induces the formation of the hydrofluoric acid (HF) due to the decomposition of $\mathrm{PF}_{6}^{-}$. The HF then migrates to the negative electrode where it reacts with the components of the SEI layer such as the $\mathrm{Li}_{2} \mathrm{CO}_{3}$.

The minimal degradation was found for the cells aging at 3 V. According to Fig. 1, at this voltage value, the positive electrode of activated carbon is at the neutral state. Therefore, undesirable mechanisms generated by the accumulation of ions at the surface of this electrode could be suppressed. As a result, the capacitance decrease and the resistance increase of these cells are much less than the ones of LiCs aging at $2.2 \mathrm{~V}$ and $3.8 \mathrm{~V}$. The electrode that would be contributing the most to the degradation of cells at $3 \mathrm{~V}$ is the negative electrode. The growth of the SEI layer would be the main aging mechanism of this electrode similarly to the cells aging at $3.8 \mathrm{~V}$ but with restrained effects. In fact, the level of lithiation of the negative electrode at $3 \mathrm{~V}$ is less that the one at $3.8 \mathrm{~V}$. Therefore, as concluded previously from [53], the negative electrode at $3.8 \mathrm{~V}$ is more damaged than the one at $3 \mathrm{~V}$.

\section{DISCUSSION}

Due to the hybrid constitution of LiCs, the effects of floating aging on their lifetime strongly depend on the level of the applied voltage. Following the results of capacitance decrease and resistance increase presented in this paper, the best storage condition of LiCs can be deduced for the first time. Whether implemented in backup systems, electric vehicles, hybrid electric vehicles or any application, LiCs at rest should be always half charged. Otherwise, their lifetime would be extremely influenced especially if they were completely discharged during their storage. Since the majority of commercial LiCs have quite similar chemical composition, this conclusion can be generalized to cover cells produced by other manufacturers. This method can reduce the cost of the overall system by limiting the failure of the LiCs. For example, in a specific application, when the LiC completes its required task, its voltage should be then maintained to $3 \mathrm{~V}$ using an appropriate management system. Therefore, severe aging consequences could be avoided. The neutral state of the positive electrode at this voltage value reduces the effects of stresses during the lifetime of LiCs.

Aging mechanisms responsible for the degradation of their performance were found by analyzing the ones in LiBs and SCs. However, at $2.2 \mathrm{~V}$, they were specific to LiCs. The irreversible adsorption of the cations $\mathrm{Li}^{+}$on the positive electrode had a significant effect on the aging acceleration. This aging mechanism would also occur during cycling of LiCs. The depth of discharge would then affect the lifespan of LiCs since low depth induces increasing adsorption. Further tests should be done in 
order to analyze this particular phenomenon happening inside the cells. Moreover, additional detailed research should be conducted in order to find the products generated during this irreversible adsorption.

Since the energy density of SCs was improved in LiCs, it is vital to compare their lifetime in adjacent conditions. In [10], the calendar aging of SCs from two manufacturers A and B, was evaluated at $60^{\circ} \mathrm{C}$ and $2.8 \mathrm{~V}$. The changes in the capacitance and the resistance are shown in Fig. 6.
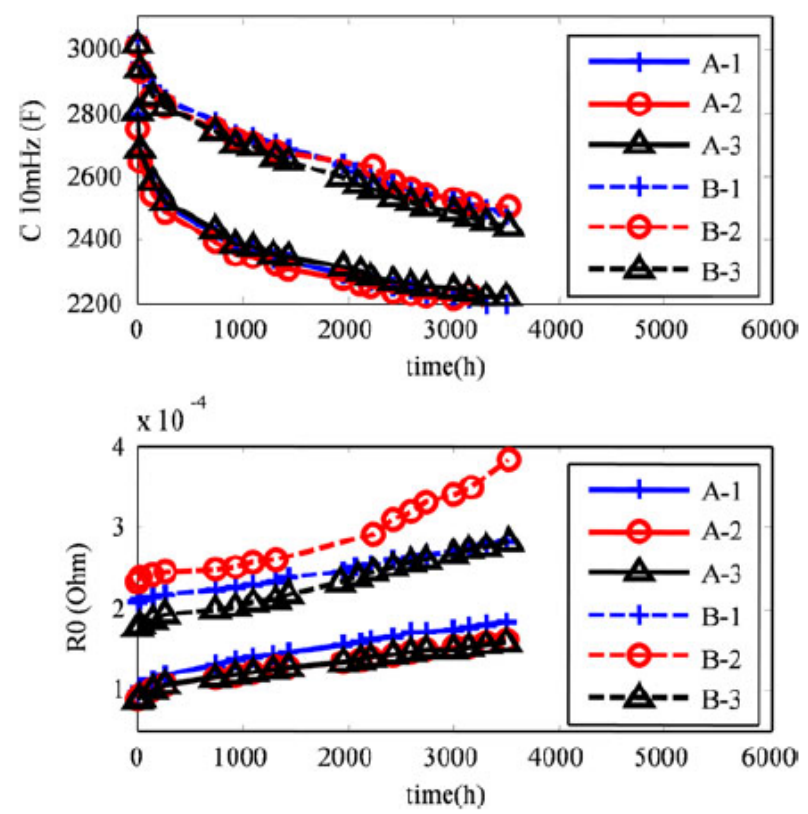

Fig. 6. Capacitance and resistance evolution of SCs aging at $2.8 \mathrm{~V}$ and $60^{\circ} \mathrm{C}[10]$.

According to this figure, the decrease of the capacitance reaches $20 \%$ after around 1500 hours of aging for cells from manufacturer A and 3100 hours for cells from manufacturer B. As for the resistance increase, the end of life criterion (increase of $100 \%$ ) was not attained. However, it is not negligible at all. Therefore, if the results presented in this paper are recalled, LiCs aging at $3 \mathrm{~V}$ and $60^{\circ} \mathrm{C}$ lost around $2.5 \%$ of capacitance after more than 14000 hours. In addition, the resistance increase was small. This confirms that the lifespan of LiCs, if stored at the optimal conditions, is much longer than that of SCs. Therefore, both energy density and lifetime are improved in LiCs. In fact, storing LiCs at $3 \mathrm{~V}$ reduces the aging of the positive electrode since it is at the approximate neutral state (Fig. 1). However a SC at $2.8 \mathrm{~V}$ has a charged positive electrode. The double layer formed at the surface of the activated carbon by the negative ions and the positive electronic charges accelerates the aging of a SC at high voltage values.

\section{CONCLUSION}

The expeditious development of new ESSs aims to satisfy power and energy requirements of advanced applications. However, the lifetime of these devices remains a critical factor that must be evaluated. The lifespan of LiCs during floating aging was 
investigated in this paper. Several voltage and temperature conditions were tested over 20 months and the results of capacitance decrease and resistance increase were analyzed. Each voltage value had a specific effect on the aging. In fact, the hybrid composition of LiCs was reflected by the voltage of the cell. At the lowest potential of the cell, the aging was extremely accelerated. The rate of the degradation of the cells was less at the highest potential but also not negligible. However, at $3 \mathrm{~V}$, which is the middle of the nominal potential window, the performance of the cells during aging was the best. Only a small decrease of the capacitance and a slight increase of the resistance were noticed. In fact, at $60^{\circ} \mathrm{C}$, the capacitance decrease was around $2.5 \%$ while at $70^{\circ} \mathrm{C}$ it was found to be around $7 \%$. In addition, the resistance increase was $4 \%$ at $60^{\circ} \mathrm{C}$ and $6 \%$ at $70{ }^{\circ} \mathrm{C}$. Therefore, according the novel results established in this paper, it is advised to maintain the voltage of LiCs at $3 \mathrm{~V}$ during their storage in order to extend their lifetime.

Aging mechanisms at different voltage values were analyzed based on the physicochemical phenomena inside LiCs. Some of them were very specific to this technology. Others were common in SCs and LiBs. According to the presented results, in order to avoid strong aging effects during storage, cells must be half charged before being left at rest. This would increase the lifetime of the cells.

For further explanations regarding the failures in LiCs, another type of accelerated aging tests will be applied in a later stage. It will be based on applying high amplitude current profiles on the cells at high temperatures. Aging effects will be then compared along with a detailed description of the possible mechanisms in both cases.

\section{REFERENCES}

[1] E. Serban, M. Ordonez, and C. Pondiche, "Voltage and Frequency Grid Support Strategies Beyond Standards," IEEE Trans. Power Electron., vol. 32, no. 1, pp. 298-309, Jan. 2017.

[2] T. Dragičević, X. Lu, J. C. Vasquez, and J. M. Guerrero, "DC Microgrids \#x2014;Part II: A Review of Power Architectures, Applications, and Standardization Issues,” IEEE Trans. Power Electron., vol. 31, no. 5, pp. 3528-3549, May 2016.

[3] I. Serban and C. Marinescu, "Control Strategy of Three-Phase Battery Energy Storage Systems for Frequency Support in Microgrids and with Uninterrupted Supply of Local Loads," IEEE Trans. Power Electron., vol. 29, no. 9, pp. 5010-5020, Sep. 2014.

[4] M. Einhorn, F. V. Conte, C. Kral, and J. Fleig, "Comparison, Selection, and Parameterization of Electrical Battery Models for Automotive Applications," IEEE Trans. Power Electron., vol. 28, no. 3, pp. 1429-1437, Mar. 2013.

[5] H. Fathabadi, "Plug-in Hybrid Electric Vehicles (PHEVs): Replacing Internal Combustion Engine with Clean and Renewable Energy Based Auxiliary Power Sources," IEEE Trans. Power Electron., vol. PP, no. 99, pp. 1-1, 2018. 
[6] A. Lahyani, A. Sari, I. Lahbib, and P. Venet, "Optimal hybridization and amortized cost study of battery/supercapacitors system under pulsed loads,” J. Energy Storage, vol. 6, pp. 222-231, May 2016.

[7] S. Hu, Z. Liang, and X. He, "Ultracapacitor-Battery Hybrid Energy Storage System Based on the Asymmetric Bidirectional Z -Source Topology for EV,” IEEE Trans. Power Electron., vol. 31, no. 11, pp. 7489-7498, Nov. 2016.

[8] O. Laldin, M. Moshirvaziri, and O. Trescases, "Predictive Algorithm for Optimizing Power Flow in Hybrid Ultracapacitor/Battery Storage Systems for Light Electric Vehicles,” IEEE Trans. Power Electron., vol. 28, no. 8, pp. 38823895, Aug. 2013.

[9] F. Savoye, P. Venet, M. Millet, and J. Groot, "Impact of Periodic Current Pulses on Li-Ion Battery Performance," IEEE Trans. Ind. Electron., vol. 59, no. 9, pp. 3481-3488, Sep. 2012.

[10] R. German, P. Venet, A. Sari, O. Briat, and J. M. Vinassa, "Improved Supercapacitor Floating Ageing Interpretation Through Multipore Impedance Model Parameters Evolution,” IEEE Trans. Power Electron., vol. 29, no. 7, pp. 3669-3678, Jul. 2014.

[11] J. Ronsmans and B. Lalande, "Combining energy with power: Lithium-ion capacitors," in 2015 International Conference on Electrical Systems for Aircraft, Railway, Ship Propulsion and Road Vehicles (ESARS), 2015, pp. 1-4.

[12] N. E. Ghossein, A. Sari, and P. Venet, "Interpretation of the Particularities of Lithium-Ion Capacitors and Development of a Simple Circuit Model,” in 2016 IEEE Vehicle Power and Propulsion Conference (VPPC), 2016, pp. 1-5.

[13] P. Kreczanik, P. Venet, A. Hijazi, and G. Clerc, "Study of Supercapacitor Aging and Lifetime Estimation According to Voltage, Temperature, and RMS Current," IEEE Trans. Ind. Electron., vol. 61, no. 9, pp. 4895-4902, Sep. 2014.

[14] M. Petit, E. Prada, and V. Sauvant-Moynot, "Development of an empirical aging model for Li-ion batteries and application to assess the impact of Vehicle-to-Grid strategies on battery lifetime,” Appl. Energy, vol. 172, pp. 398-407, June 2016.

[15] A. Eddahech, O. Briat, E. Woirgard, and J. M. Vinassa, "Remaining useful life prediction of lithium batteries in calendar ageing for automotive applications,” Microelectron. Reliab., vol. 52, no. 9-10, pp. 2438-2442, Sep. 2012.

[16] M. Swierczynski, D. I. Stroe, A. I. Stan, R. Teodorescu, and S. K. Kær, "Lifetime Estimation of the Nanophosphate Battery Chemistry Used in Fully Electric Vehicles,” IEEE Trans. Ind. Appl., vol. 51, no. 4, pp. 3453-3461, Jul. 2015.

[17] A. E. Mejdoubi, A. Oukaour, H. Chaoui, H. Gualous, J. Sabor, and Y. Slamani, "State-of-Charge and State-of-Health Lithium-Ion Batteries \#x2019; Diagnosis According to Surface Temperature Variation,” IEEE Trans. Ind. Electron., vol. 63, no. 4, pp. 2391-2402, Apr. 2016.

[18] X. Hu, J. Jiang, D. Cao, and B. Egardt, "Battery Health Prognosis for Electric Vehicles Using Sample Entropy and Sparse Bayesian Predictive Modeling," IEEE Trans. Ind. Electron., vol. 63, no. 4, pp. 2645-2656, Apr. 2016. 
[19] A. Hammar, P. Venet, R. Lallemand, G. Coquery, and G. Rojat, "Study of Accelerated Aging of Supercapacitors for Transport Applications,” IEEE Trans. Ind. Electron., vol. 57, no. 12, pp. 3972-3979, Dec. 2010.

[20] S. Grolleau et al., "Calendar aging of commercial graphite/LiFePO4 cell - Predicting capacity fade under time dependent storage conditions," J. Power Sources, vol. 255, pp. 450-458, June 2014.

[21] R. B. Wright et al., "Calendar- and cycle-life studies of advanced technology development program generation 1 lithium-ion batteries," J. Power Sources, vol. 110, no. 2, pp. 445-470, Aug. 2002.

[22] N. Rizoug, R. Sadoun, T. Mesbahi, P. Bartholumeus, and P. LeMoigne, "Aging of high power Li-ion cells during real use of electric vehicles," IET Electr. Syst. Transp., vol. 7, no. 1, pp. 14-22, 2017.

[23] D. I. Stroe, M. Świerczyński, A. I. Stan, R. Teodorescu, and S. J. Andreasen, “Accelerated Lifetime Testing Methodology for Lifetime Estimation of Lithium-Ion Batteries Used in Augmented Wind Power Plants," IEEE Trans. Ind. Appl., vol. 50, no. 6, pp. 4006-4017, Nov. 2014.

[24] R. German, A. Sari, O. Briat, J. M. Vinassa, and P. Venet, "Impact of Voltage Resets on Supercapacitors Aging,” IEEE Trans. Ind. Electron., vol. 63, no. 12, pp. 7703-7711, Dec. 2016.

[25] M. Uno and A. Kukita, "Cycle Life Evaluation Based on Accelerated Aging Testing for Lithium-Ion Capacitors as Alternative to Rechargeable Batteries,” IEEE Trans. Ind. Electron., vol. 63, no. 3, pp. 1607-1617, Mar. 2016.

[26] S. Barcellona, F. Ciccarelli, D. Iannuzzi, and L. Piegari, "Overview of Lithium-ion Capacitor Applications Based on Experimental Performances,” Electr. Power Compon. Syst., vol. 44, no. 11, pp. 1248-1260, Jul. 2016.

[27] H. Gu, Y.-E. Zhu, J. Yang, J. Wei, and Z. Zhou, "Nanomaterials and Technologies for Lithium-Ion Hybrid Supercapacitors,” ChemNanoMat, vol. 2, no. 7, pp. 578-587, Jul. 2016.

[28] A. Shellikeri, I. Hung, Z. Gan, and J. Zheng, "In Situ NMR Tracks Real-Time Li Ion Movement in Hybrid SupercapacitorBattery Device,” J. Phys. Chem. C, vol. 120, no. 12, pp. 6314-6323, Mar. 2016.

[29] S. R. Sivakkumar and A. G. Pandolfo, "Evaluation of lithium-ion capacitors assembled with pre-lithiated graphite anode and activated carbon cathode,” Electrochimica Acta, vol. 65, pp. 280-287, Mar. 2012.

[30] W. Cao, "Novel High Energy Density Li-Ion Capacitors,” 2013.

[31] S. R. Sivakkumar, V. Ruiz, and A. G. Pandolfo, “Assembly and testing of lithium-ion capacitors,” 2010

[32] Q.-C. Zhuang, X.-Y. Qiu, S.-D. Xu, Y.-H. Qiang, and S.-G. Sun, "Diagnosis of Electrochemical Impedance Spectroscopy in Lithium-Ion Batteries," 2012.

[33] S. Buller, E. Karden, D. Kok, and R. W. D. Doncker, "Modeling the dynamic behavior of supercapacitors using impedance spectroscopy,” IEEE Trans. Ind. Appl., vol. 38, no. 6, pp. 1622-1626, Nov. 2002. 
[34] S. Socher, C. Jehle, and U. Potthoff, "Improving the Functional Safety of Automotive Batteries Using in-situ Impedance Spectroscopy,” Transp. Res. Procedia, vol. 14, pp. 3661-3666, Jan. 2016.

[35] S. Shili, A. Sari, A. Hijazi, and P. Venet, “Online lithium-ion batteries health monitoring using balancing circuits," in 2017 IEEE International Conference on Industrial Technology (ICIT), 2017, pp. 484-488.

[36] N. E. Ghossein, A. Sari, and P. Venet, "Nonlinear Capacitance Evolution of Lithium-Ion Capacitors Based on Frequency and Time Domain Measurements," IEEE Trans. Power Electron., vol. PP, no. 99, pp. 1-1, 2017.

[37] T. Guan et al., "The effect of elevated temperature on the accelerated aging of LiCoO2/mesocarbon microbeads batteries," Appl. Energy, vol. 177, pp. 1-10, Sep. 2016.

[38] E. Redondo-Iglesias, P. Venet, and S. Pelissier, "Eyring acceleration model for predicting calendar ageing of lithium-ion batteries," J. Energy Storage, vol. 13, no. Supplement C, pp. 176-183, Oct. 2017.

[39] P. Keil and A. Jossen, "Calendar Aging of NCA Lithium-Ion Batteries Investigated by Differential Voltage Analysis and Coulomb Tracking,” J. Electrochem. Soc., vol. 164, no. 1, pp. A6066-A6074, Jan. 2017.

[40] E. Sarasketa-Zabala, I. Gandiaga, L. M. Rodriguez-Martinez, and I. Villarreal, "Calendar ageing analysis of a LiFePO4/graphite cell with dynamic model validations: Towards realistic lifetime predictions,” J. Power Sources, vol. 272, pp. 45-57, Dec. 2014.

[41] S. Grolleau, A. Delaille, and H. Gualous, "Predicting lithium-ion battery degradation for efficient design and management," in 2013 World Electric Vehicle Symposium and Exhibition (EVS27), 2013, pp. 1-6.

[42] A. Eddahech, O. Briat, and J.-M. Vinassa, "Performance comparison of four lithium-ion battery technologies under calendar aging,” Energy, vol. 84, pp. 542-550, May 2015.

[43] C. Lin, A. Tang, H. Mu, W. Wang, C. Wang, “Aging mechanisms of electrode materials in lithium-ion batteries for electric vehicles, ” Journal of Chemistry, 2015.

[44] J. Vetter et al., “Ageing mechanisms in lithium-ion batteries,” J. Power Sources, vol. 147, no. 1, pp. 269-281, Sep. 2005.

[45] V. A. Agubra and J. W. Fergus, "The formation and stability of the solid electrolyte interface on the graphite anode," J. Power Sources, vol. 268, pp. 153-162, Dec. 2014.

[46] A. Barré, B. Deguilhem, S. Grolleau, M. Gérard, F. Suard, and D. Riu, “A review on lithium-ion battery ageing mechanisms and estimations for automotive applications," J. Power Sources, vol. 241, pp. 680-689, Nov. 2013.

[47] C. Julien, A. Mauger, A. Vijh, and K. Zaghib, Lithium Batteries: Science and Technology. Springer International Publishing, 2016.

[48] V. Khomenko, E. Raymundo-Piñero, and F. Béguin, "High-energy density graphite/AC capacitor in organic electrolyte,” J. Power Sources, vol. 177, no. 2, pp. 643-651, Mar. 2008. 
[49] Y. Parvini, J. B. Siegel, A. G. Stefanopoulou, and A. Vahidi, "Supercapacitor Electrical and Thermal Modeling, Identification, and Validation for a Wide Range of Temperature and Power Applications," IEEE Trans. Ind. Electron., vol. 63, no. 3, pp. 1574-1585, Mar. 2016.

[50] M. Jahandar Lashaki, J. D. Atkinson, Z. Hashisho, J. H. Phillips, J. E. Anderson, and M. Nichols, "The role of beaded activated carbon's surface oxygen groups on irreversible adsorption of organic vapors,” J. Hazard. Mater., vol. 317 , pp. 284-294, Nov. 2016.

[51] P. Azaïs et al., "Causes of supercapacitors ageing in organic electrolyte,” J. Power Sources, vol. 171, no. 2, pp. 1046-1053, Sep. 2007.

[52] Y. Liu, B. Soucaze-Guillous, P.-L. Taberna, and P. Simon, "Understanding of carbon-based supercapacitors ageing mechanisms by electrochemical and analytical methods," J. Power Sources, vol. 366, pp. 123-130, Oct. 2017.

[53] P. Keil et al., "Calendar Aging of Lithium-Ion Batteries I. Impact of the Graphite Anode on Capacity Fade,” J. Electrochem. Soc., vol. 163, no. 9, pp. A1872-A1880, Jan. 2016.

[54] T. Zhang, B. Fuchs, M. Secchiaroli, M. Wohlfahrt-Mehrens, and S. Dsoke, "Electrochemical behavior and stability of a commercial activated carbon in various organic electrolyte combinations containing Li-salts," Electrochimica Acta, vol. 218, pp. 163-173, Nov. 2016.

[55] P. W. Ruch, D. Cericola, M. Hahn, R. Kötz, and A. Wokaun, "On the use of activated carbon as a quasi-reference electrode in non-aqueous electrolyte solutions," J. Electroanal. Chem., vol. 636, no. 1, pp. 128-131, Nov. 2009.

[56] M. Widmaier et al., "Carbon as Quasi-Reference Electrode in Unconventional Lithium-Salt Containing Electrolytes for Hybrid Battery/Supercapacitor Devices,” J. Electrochem. Soc., vol. 163, no. 14, pp. A2956-A2964, Jan. 2016.

[57] K. Okuno, K. Takahashi, M. Majima, and M. Ishikawa, "Lithium ion capacitor and method for charging and discharging same,” EP2978002 A4, 26-Oct-2016.

[58] T. Aida, I. Murayama, K. Yamada, and M. Morita, “Analyses of Capacity Loss and Improvement of Cycle Performance for a High-Voltage Hybrid Electrochemical Capacitor,” J. Electrochem. Soc., vol. 154, no. 8, pp. A798-A804, Jan. 2007. 